\title{
Nuevos desafíos entre el discurso oficial y local del patrimonio cultural inmueble
}

New Challenges between the Official and Local

Discourse of the Cultural Heritage Property

Novos desafios entre o discurso oficial e local sobre o patrimônio cultural do imóvel

Germán Jaramillo Uribe ${ }^{*}$

Recibido: 26 de junio del 2019

Aprobado: 24 de agosto del 2020

https://doi.org/10.12804/revistas.urosario.edu.co/territorios/a.8033

Para citar este artículo:

Jaramillo Uribe, G. (2021). Nuevos desafíos entre el discurso oficial y local del patrimonio cultural inmueble. Territorios, (44), 271-291. https://doi.org/10.12804/revistas.urosario.edu.co/territorios/a.8033

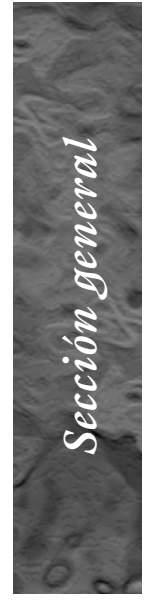

* Docente investigador, Universidad de San Buenaventura (Medellín). Correo electrónico: german.jaramillo@usbmed. edu.co. ORCID: https:// orcid.org/0000-00018350-8800 
Palabras clave

Discurso local; discurso oficial; Ferrocarril de Antioquia; gestión del patrimonio; identidad; participación; patrimonio.

Keywords Official discourse; local discourse; beritage; identity; beritage management; participation; Antioquia railway.

Palavras-chave Discurso oficial; discurso local; patrimônio; identidade; gestão do patrimônio; participação; Ferrovia da Antioquia.

territarias 44

\section{RESUMEN}

El presente artículo plantea el debate entre el discurso oficial autorizado y el discurso local en los procesos de valoración y gestión del patrimonio como construcción social, contrastado con la experiencia del proyecto de gestión patrimonial del Ferrocarril de Antioquia, en la categoría de itinerario cultural, como respuesta a las siguientes preguntas: ¿Cuáles son las contradicciones en los procesos de gestión del patrimonio urbano-arquitectónico? Y ¿Cuáles son los desafíos en la construcción, resignificación y activación del patrimonio cultural desde los discursos e identidades locales? Pone de relieve la disyuntiva desde lo teórico y lo práctico, e invita a encontrar nuevas estrategias de gestión participativa que permitan generar procesos de legitimación social del patrimonio, entendidos en el marco de la cultura como un agente de cambio en doble vía, que atienda tanto a la puesta en valor de los patrimonios locales, como al fomento de nuevas identidades individuales y colectivas.

\section{ABSTRACT}

This article poses the debate between the authorized official discourse and the local discourse in the processes of cultural heritage valuation and management as a social construction, contrasted with the experience of the heritage management project of Antioquia's railway in the category of cultural itinerary, as a response to the following questions: ¿What are the contradictions in the management processes of urban-architectural heritage?, and, ¿what are the challenges in the construction, resignification and activation of cultural heritage from local discourses and identities? It highlights the dilemma, from the theoretical and practical, and invites to find new participatory management strategies that allow generating processes of heritage social legitimation, understood within the framework of culture as a two-way agent of change, which addresses both the enhancement of local heritage, as well as the promotion of new individual and collective identities.

\section{RESUMO}

O presente artigo propõe o debate entre o discurso oficial autorizado e o discurso local sobre os processos de valorização e gestão do patrimônio como construção social. Em contraste com a experiência do projeto de gestão patrimonial da ferrovia de Antioquia na categoria de itinerário cultural, como resposta às seguintes perguntas: quais são as contradições dos processos de gestão do patrimônio urbano-arquitetônico? Quais são os desafios na construção, ressignificação e ativação do patrimônio cultural a partir dos discursos e identidades locais? Destaca o dilema entre teoria e prática, e convida a buscar novas estratégias de gestão participativa que permitam gerar processos de legitimação social do patrimônio, entendido dentro da estrutura da cultura como um agente de mudança de vida em ambos sentidos, que atenda tanto a valorização dos patrimônios locais, quanto o fomento de novas identidades individuais e coletivas. 
[...] Soy, pero soy también el otro. Fragmento de El otro, el mismo (Jorge Luis Borges)

\section{Situación problema}

Las relaciones entre identidad cultural y patrimonio en su asociación al territorio, plantean la necesidad de establecer un correlato entre el discurso local ${ }^{1}$ y el discurso oficial. ${ }^{2}$ Se parte de la idea que lo patrimonial como invención, no excluye su condición previa de identidad, asumida como expresión de la cultura, mientras que la identidad cultural existe per se, es auténtica, se construye y resignifica de manera permanente, sin que sea necesario algún artilugio para su reconocimiento. Desde esta perspectiva, lo patrimonial se adscribe históricamente a la necesidad de validar lo que social y culturalmente ya ha sido legitimado, y por ello, se incorpora al discurso oficial autorizado como un instrumento de poder sobre los bienes culturales que los Estados han venido perpetuando para su discurso hegemónico de nacionalidad. En la ética eurocéntrica decimonónica del discurso patrimonial autorizado, el patrimonio "debe conservarse como ha llegado a las nuevas generaciones" (Ruskin \& Morris citados en Smith, 2011, p. 43), lo que le confiere su carácter de "cosa", lugar o monumento, que al final lo separa de los valores culturales inherentes y le extrae de su condición dinámica y holística en la interdependencia que establece entre su esencia material e inmaterial.

Otra variante en la versión oficial del discurso - que se aprovecha de esta condición-, son los fenómenos especulativos del suelo y las presiones inmobiliarias que se ejercen especialmente en los centros y entornos históricos consolidados, en el interés por un tendencioso ordenamiento territorial que privilegia las grandes operaciones urbanas de redensificación y mercantilización del suelo o, en un escenario más amplio, los grandes megaproyectos de infraestructuras de movilidad urbana y territorial: sistemas de transporte masivo, proyectos viales y autopistas $4 \mathrm{G}$; así como la explotación desmedida de los recursos naturales en las zonas rurales: minería a cielo abierto, monocultivos y agroindustria extensiva acompañada de deforestación en las zonas selváticas $\mathrm{y}$, licencias ambientales para la construcción de micro y mega centrales hidroeléctricas - entre las más representativas en el contexto colombiano- - Negando toda posibilidad de interacción con el patrimonio urbano, natural y paisajístico que se ha afianzado con esplendor en la perspectiva histórica y cultural de la nación.

Desde lo oficial, lo patrimonial es reflejo de nacionalidad y excepcionalidad, ${ }^{3}$ y se termina de validar por su condición finita, frágil y no renovable, al igual que los recursos naturales. Su conservación se constituye en la carta de navegación de los gobiernos, entendido el patrimonio
${ }^{1}$ El discurso local se interpreta como la construcción de identidad que nace, se modela y consolida en las cotidianidades e interacciones de los sujetos sociales, derivadas de la memoria y prácticas culturales. Se expresa a través de los imaginarios urbanos $y$ apropiaciones colectivas en el espacio tiempo, sobre las cuales se atribuyen valoraciones simbólicas y significativas en los contextos locales.

${ }^{2}$ La noción de discurso oficial, en el contexto que nos ocupa, tiene origen en la idea del "discurso patrimonial autorizado", y se construye a partir de las versiones arqueológica $y$ monumentalista, heredadas de la Europa del siglo $X I X$, que plantea una mirada estática, hegemónica $y$ oficialista de las versiones de identidad, que si bien, en principio pueden tener valor de legitimad, se apartan de los procesosy dinámicas socioculturales de resignificación y apropiación.

${ }^{3}$ La última actualización del Ministerio de Cultura (2008) que se hace a la Ley General de Cultura 397 (1997) sobre la definición de los bienes que integran el patrimonio cultural de $\Longrightarrow$

territarias 44 273 
$\Leftarrow$

la nación, dice: "El patrimonio cultural de la Nación está constituido por todos los bienes materiales, las manifestaciones inmateriales, los productos $y$ las representaciones de la cultura que son expresión de la nacionalidad colombiana, tales como la lengua castellana, las lenguas y dialectos de las comunidades indigenas, negras y creoles, la tradición, el conocimiento ancestral, el paisaje cultural, las costumbres y los hábitos, así como los bienes materiales de naturaleza mueble e inmueble a los que se les atribuye, entre otros, especial interés histórico, artístico, científico, estético o simbólico en ámbitos como el plástico, arquitectónico, urbano, arqueológico, lingüístico, sonoro, musical, audiovisual, filmico, testimonial, documental, literario, bibliográfico, museológico o antropológico" (Las redondas son mias).

Así mismo, en la Ley 397 se establece que son el Gobierno y las entidades territoriales -dependiendo de la escala de declaratoria del Bien de Interés Cultural (BIC)en quienes recae los procesos de declaratoria

$\Longrightarrow$

\section{territarios 44} 274 como herencia y extensión de las futuras generaciones. En esos procesos de legitimación de lo patrimonial, se han excluido las voces de los actores y algunos atributos de valor asociados al contexto histórico, sociocultural y territorial donde se insertan, desencadenando fraccionamientos y debilitamiento de su presencia histórica en las geografías y paisajes urbanos y regionales. Como contra parte a su intención "conservacionista", se está vivenciando un fenómeno gradual y sistemático de pérdida de representatividad y riesgo de extinción. Mientras lo patrimonial no sea una construcción social, sino una invención amparada en las ideologías e historias dominantes, en una especie de "ilusión narcisista por el monumento" (Choay \& Connell, 2001), su capacidad autónoma de perpetuarse, activarse y actualizarse se desvanece. Esto no exime al Estado de su responsabilidad de protegerlo y encontrar mecanismos que permitan promover estrategias y, diseñar instrumentos orientados hacia su gestión y puesta en valor, tales como los Planes Especiales de Manejo y Protección (PEMP), con un ingrediente de participación ciudadana más visible, efectivo y sostenible.

No existe un desarrollo teórico o algún cuerpo doctrinal que permita reconocer las líneas sobre la cual se fundamenta la gestión incluyente del patrimonio cultural, en cambio sí un desarrollo teórico de la historia, la conservación y restauración, que ha evolucionado de una mirada singular y monumentalista, a una versión compleja inter y transdisciplinar, que apoyada en las ciencias sociales, ha permeado el discurso de la materialidad de los monumentos a la integralidad de sus contenidos en su contexto histórico y socio cultural.

La identidad cultural, en cambio, habla de un discurso local que se ha construido palmo a palmo y que se ha legitimado socialmente, sin la necesidad de apoyarse en la oficialidad para su reconocimiento. Este proceso libera los bienes de interés cultural de todo paradigma monumentalista o mercantilista, amparado en las ideologías e historias dominantes, lo sitúa en el campo de las apropiaciones y significaciones de los imaginarios sociales, y por ende, de la función del patrimonio como rédito social. Lo anterior obliga a hablar de la gestión o activación del patrimonio, más allá de la conservación por la conservación.

Lo mencionado no descalifica que la idea de las identidades - como discurso local—, y el patrimonio - como discurso oficial-, pueda coexistir y complementarse sobre la base del patrimonio como constructo social en permanente resignificación, sin alterar los valores que le han dado legitimidad en su relación estrecha con el territorio, las comunidades y la cultura. Esto implica replantearse la pregunta: ¿Cómo se genera identidad cultural en la ciudad a través del patrimonio?, por ¿Cómo se construye el patrimonio desde las identidades locales?, lo que implica un enfoque complejo, renovado, abarcador, incluyente y dinamizador del patrimonio como rédito social. 


\section{El paradigma participacionista del patrimonio}

Incorporar a la lectura singular y monumentalista de los bienes de interés cultural, una mirada integral al territorio y contexto socio-cultural, como las valoraciones derivadas de las apropiaciones y significaciones $\mathrm{y}$, los procesos de creación y representación en el imaginario de las comunidades, se está constituyendo en una tarea prioritaria. Para ello, necesita de protocolos incluyentes de participación que permitan completar los discursos y procesos de patrimonialización que han sido exclusivos de una élite académica y de poder, que ha invocado el discurso oficial de nacionalidad y monumentalidad por encima de la condición especial y significativa del locus, en asocio con lo local en su condición existencial. Un elemento de peso en la reflexión epistemológica que deriva del "espacio" como hecho existencial en el estrecho vínculo con su condición patrimonial, plantea la necesidad de generar espacios de diálogo ampliados en el espacio-tiempo con la memoria del lugar (herencias) y sus actores (imaginarios). En palabras de Santos (2000):

[...] Paisaje y espacio no son sinónimos. El paisaje es el conjunto de formas que, en un momento dado, expresa las herencias que representan las sucesivas relaciones localizadas entre hombre y naturaleza. El espacio es la reunión de estas formas, más la vida que las anima (p. 86).
Con ello se invoca la dialéctica entre las teorías sociales y geográficas que plantea Milton Santos, toda vez que incorpora categorías de base existencialista para explicar las relaciones de interacción entre el paisaje y el espacio, tan necesarias en la configuración del patrimonio en su estrecha relación con el territorio, la comunidad y la cultura. En esta medida se alude al paisaje como las herencias (memoria), más "la vida que las anima" (espacio), para invocar un discurso que, al presente, debe construirse desde las cotidianidades e imaginarios sociales.

Desde la legislación cultural, como herramienta para la conservación del patrimonio, hoy renovada en la perspectiva de la activación o puesta en valor de los Bienes de Interés Cultural (BIC) como estrategia de gestión - el caso de los PEMP-, no se hacen efectivos los mecanismos de participación que permitan vincular dichos bienes a las dinámicas de desarrollo territorial, desde una perspectiva incluyente con los ciudadanos. El tema de la participación no es un asunto de política pública, y por ello, termina marginado de los procesos de gestión en los centros históricos. En un marco más amplio, la Unesco, en su Conferencia Intergubernamental sobre Políticas Culturales para el Desarrollo (1998), se centra en la idea de la cultura como base del desarrollo y remite al Decenio Mundial para el Desarrollo Cultural “[...] afirmando e intensificando las identidades culturales, ampliando la participación en $y$ manejo del patrimonio cultural, representado en los monumentos nacionales o los bienes de interés cultural, y aclara textualmente, que para su validación se haga "previo concepto de los centros filiales del Consejo de Monumentos Nacionales alli donde existan, o en su defecto por la entidad delegada por el Ministerio de Cultura” (Ley 397, 1997, art. 8), lo que demuestra con claridad, la poca capacidad de maniobra y autonomía de las entidades locales, toda vez se recae en la versión oficialista del patrimonio, sin permear los discursos y procesos autónomos de las localidades.

territarias 44 275 
la vida cultural y, promoviendo la cooperación cultural internacional" (Unesco, 1998, p. 12). Dentro de los principios reconocidos en la Conferencia y, que son vinculantes con la gestión del patrimonio cultural, se señalan: la interdependencia entre la cultura y el desarrollo sostenible, los procesos democráticos de inclusión y participación ciudadana en la vida cultural, el diálogo intercultural como condición para la coexistencia pacífica, el desarrollo de la creatividad cultural, el equilibrio armónico entre cultura y desarrollo y, la defensa de las culturas locales y regionales, sin que se vean opacadas por la cultura de la globalización (Unesco, 1998). Lo más paradójico en las políticas neoliberales de gestión del territorio, es que van en contravía con estos principios, en las alianzas tácitas que se establecen entre las administraciones públicas y privadas, se evidencia una forma sistemática de entorpecer los ejercicios de declaratoria y patrimonialización - cuando no se decide su eliminación por acto administrativo-, mucho más evidente si en estos procesos se incluyen actores sociales como protagonistas en la discusión. Parte de los argumentos que descalifican las voces de los actores comunitarios, radica en el falso mito y temor a que sus valoraciones sobre el patrimonio se constituyan en un lastre para el desarrollo, máxime si somete a ecuaciones de rentabilidad y mercantilización del suelo. Lo anterior, a la vista de ciudadanos inermes, conscientes del valor que le asignan a sus bienes, pero inocentes frente al conocimiento de las herramientas para su protección, lo que plantea la necesidad del aprendizaje de la Ley General de Cultura como cátedra pendiente en la formación de ciudadanos.

De allí que las iniciativas derivadas de la ciudadanía a través de los colectivos sociales, culturales, artísticos y académicos, respaldadas por la gestión público-privada desde la escala local, sean un camino de negociación en los procesos de inventario, valoración e intervención del patrimonio. El encuentro desigual entre la cultura y el desarrollo, llevado a la gestión del patrimonio, impulsa a entender estos procesos en su transversalidad como acciones de fortalecimiento de un discurso patrimonial permeado por el desarrollo desde lo local, que se incorpora a los discursos oficiales como propuesta renovadora y trasformadora del territorio. El paradigma participacionista, es una estrategia de desarrollo sustentable en la cual todos caben y pueden asumir roles sociales e individuales sobre la base del bien común, en equilibro con la naturaleza y el territorio.

\section{Lecciones aprendidas y contradicciones}

Lo que para Prats (2005) representa la "puesta en valor o activación patrimonial", abre la posibilidad de considerar, según el autor, el discurso de la activación en sus reglas gramaticales de selección, ordenación e interpretación, esta última como sinónimo de gestión patrimonial en conjunto. En 
torno a dicho discurso, el autor plantea un segundo plano de negociación, que parte de la memoria e imaginarios compartidos, como representación y creación sociocultural que solo se hacen presentes a través de procesos de participación en los cuales todos los actores se sientan en la misma mesa y establecen un diálogo abierto de saberes y reconocimiento de capacidades.

La experiencia del proyecto de gestión patrimonial del Ferrocarril de Antioquia, en la categoría patrimonial de itinerario cultural (Jaramillo Uribe, 2016) en el marco de la investigación y acción participativa, ha permitido ampliar el espectro cotidiano y pragmático de gestión, a la mirada contextual y holística del territorio como espacio "percibido, sentido y vivido" (Comerci, 2004, p. 159), estableciendo un lugar común, cargado de valoraciones compartidas inobjetables en el debate y disputa del territorio.

A continuación, se indican algunas estrategias adelantadas en el proceso de valoración y gestión participativa del Ferrocarril de Antioquia, en su activación como categoría patrimonial de itinerario cultural, tales como el desarrollo de talleres de formación de vigías de patrimonio y sesiones de trabajo comunitario, para invocar la memoria en interacción con el territorio y su prospectiva (figuras, 1, 2 y 3):

- "Contar y recrear. La imagen invita a la palabra": dirigida a grupos de adultos y adultos mayores, emplea el recurso de la fotografía como pretexto para invocar la palabra en forma de historias de vida.

- "Sonidos de la memoria": dirigida a adultos mayores, permite asociar valoraciones simbólicas y conmemorativas con una profunda carga afectiva, por medio de estimulaciones de tipo sensorial (sonidos pregrabados de pitos de locomotoras).

- "Inventarios de arqueología industrial": dirigido a un público de jóvenes $\mathrm{y}$ adultos, son procesos de reconocimiento en campo de la mano de pobladores, pensionados del ferrocarril y habitantes de la zona, en el cual se descubren nuevas evidencias que nutren el discurso local del patrimonio. Elementos que formaron parte del sistema ferroviario y que permiten explicar las razones de su implantación $\mathrm{y}$ funcionamiento dentro del sistema y operación: acueductos, puentes, sistemas de comunicaciones, elementos etnográficos, camino, hitos del paisaje, entre otros.

- “Tejiendo imágenes e historias, el expreso del tiempo": dirigido a un público más amplio de jóvenes y adultos, usa la técnica del collage como recurso para construir historias colectivas y prácticas asociadas a la cultura ferroviaria — formas productivas y de intercambio comercial, apropiaciones de lugares, fiestas patronales y conmemorativas, entre otras-.

- "Cartografía de los sueños y de las emociones": dirigido a un público territarios 44 277 
joven, ávido para expresar con manualidades sus sentimientos, apropiaciones y expectativas sobre los lugares cotidianos.

Figura 1. Vestigios de acueducto del Ferrocarril de Antioquia
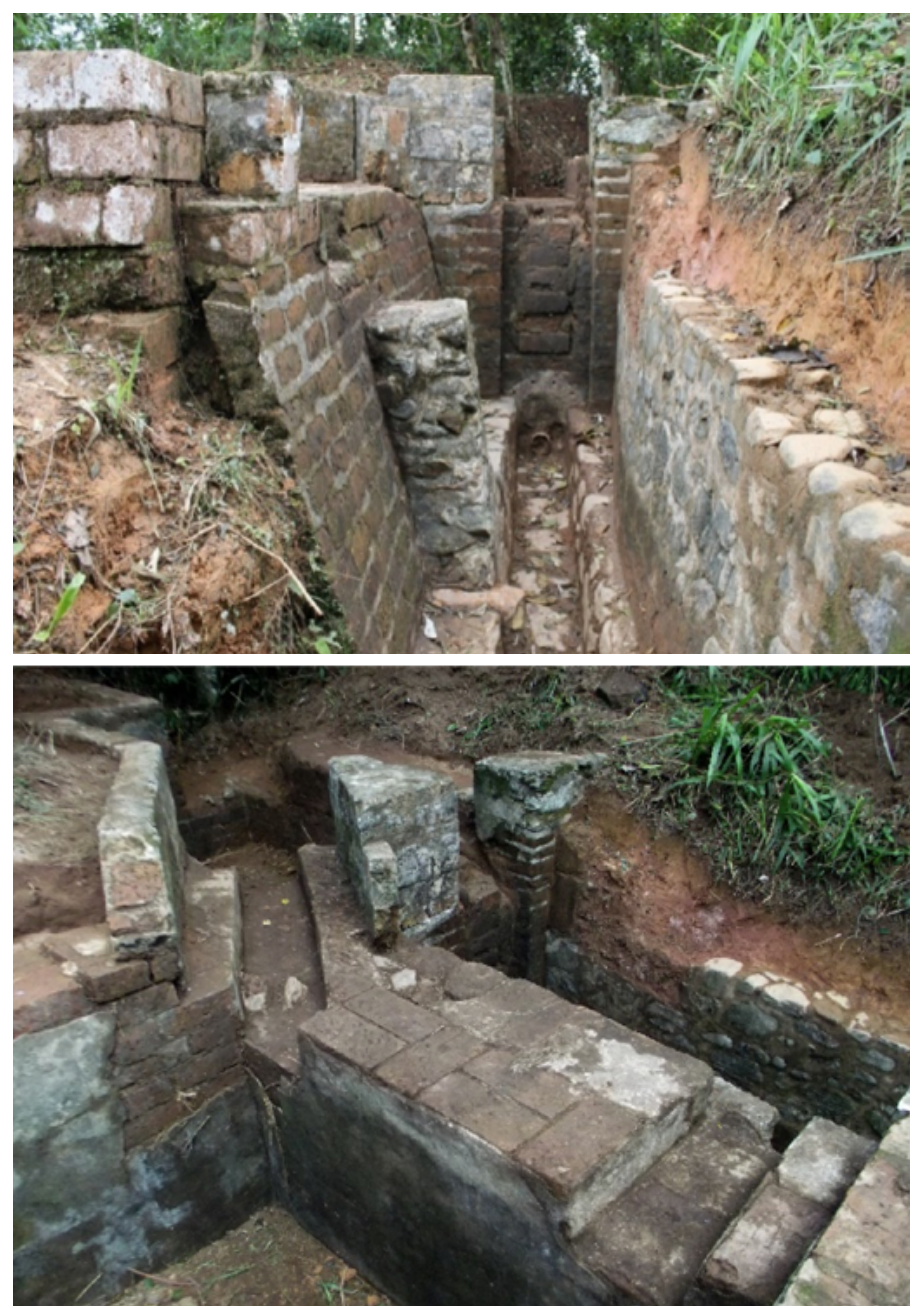

territarias 44

Nota: estos vestigios fueron encontrados en la prospección arqueológica realizada en las inmediaciones de la estación Botero. Hoy forma parte del inventario de arqueología industrial y ferroviaria del ICANH. 
Figura 2. Taller con grupo de vigías de patrimonio en la estación El Limón

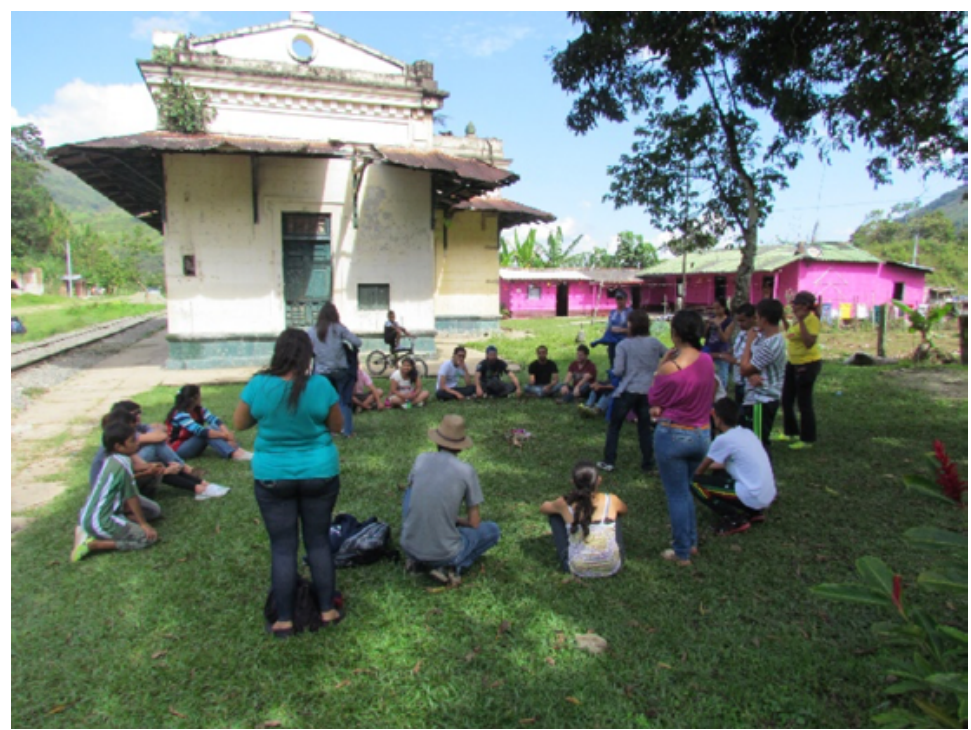

Fuente: elaboración propia (2013).

Figura 3. Taller con grupo de vigías de patrimonio en la estación Cisneros

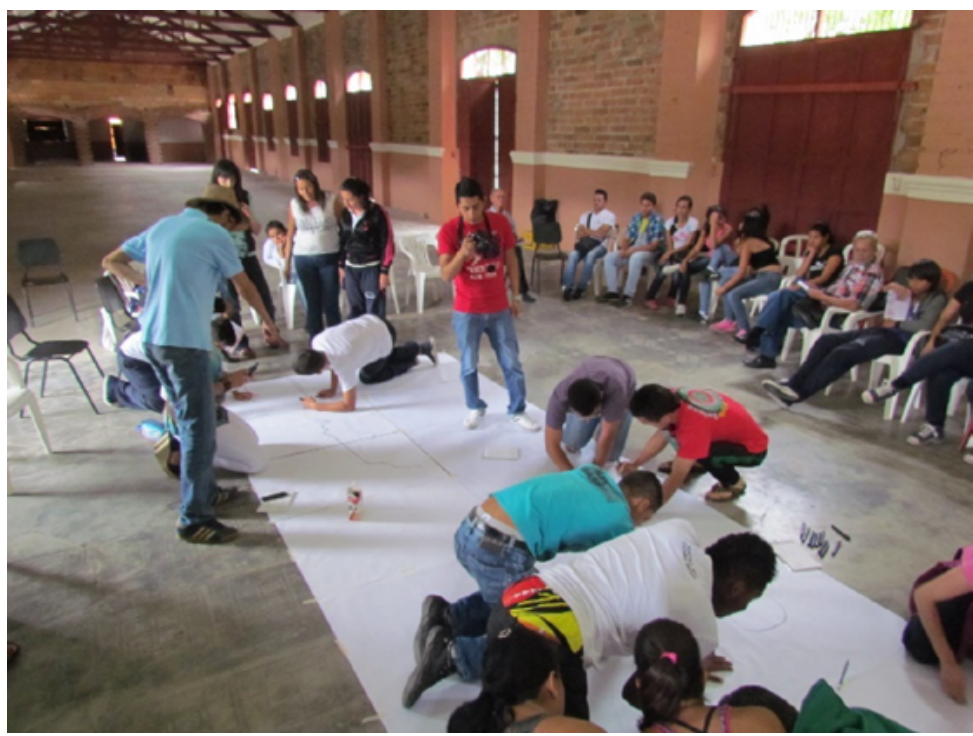

Fuente: elaboración propia (2013).

territarias 44 
En realidad, los procesos de gestión del patrimonio están guiados por el discurso oficial con un enfoque reduccionista de mercado, que tiende, cada vez más, al abandono y derribo de las preexistencias históricas del patrimonio cultural inmueble, y en el mejor de los casos, a su dispersión y aislamiento de la estructura urbana. El patrimonio moderno es uno de los primeros en ser excluido, y con ello, las evidencias del patrimonio industrial y ferroviario. En este caso, el Ferrocarril de Antioquia da cuenta de esta problemática.

En ese sentido, desde la declaratoria que hace el Ministerio de Cultura (Resolución n. ${ }^{\circ} 13$ de 1994) sobre las estaciones del ferrocarril como bienes de interés cultural de nación, excluyen de la selección todas las obras complementarias que han sido parte integral de los conjuntos ferroviarios como talleres, bodegas, casas de jefe de estación, capillas, profilácticos, campamentos, hoteles y hospitales - entre las más comunes y representativas-; y las infraestructuras civiles complementarias como el trazado de la vía, puentes, acueductos y sistemas de alimentación de agua para vaporinas, mesas giratorias, patios de maniobra, túneles, microcentrales de energía, entre otros. Todo lo anterior, está integrado a la ruta como categoría patrimonial de itinerario cultural, lo cual involucra el resto de las manifestaciones y prácticas culturales asociadas a la memoria ferroviaria como la gastronomía, la música de carrilera y las fiestas patronales de la virgen del Carmen, que aún, en la obsolescencia del sistema ferroviario, cobran vigencia en las comunidades. La vía férrea ha mantenido su vocación de servidumbre y es utilizada de forma artesanal y espontánea como medio de transporte por las comunidades, lo cual prueba su vigencia y valor de uso.

Por otra parte, lo dicho ha permitido demostrar lo limitado y reducido del discurso oficial, que solo se ciñe, en este caso, a elementos materiales aislados sin considerar el contexto donde se inscriben. Son múltiples los casos de conjuntos mutilados y arrasados donde, con suerte, la única evidencia física que queda en pie es la estación que se ha mantenido en gracia de su declaratoria como BIC de la nación, pero en desafortunada desgracia por perder su esencia como conjunto en buena parte, por la inexistencia de un plan especial de protección asociado a la zona de influencia, lo que termina alterando aún más su imagen y presencia en el paisaje (figuras 4 y 5 ).

Uno de los hitos más representativos de la infraestructura ferroviaria del departamento de Antioquia, construido en la primera mitad del siglo XX en el momento de mayor esplendor de la empresa, lo constituyen los Talleres del ferrocarril en el municipio de Bello. Son uno de los pocos complejos ferroviarios en el país que aún conservan su integralidad física, constituyéndose en un referente de la memoria histórica del departamento de Antioquia, que pese a su impacto en el desarrollo territorial, urbanístico, tecnológico, social y económico, aún no figura en la lista de interés cultural de la nación. Sin embargo, 
forma parte del repertorio singular de la ingeniería y arquitectura moderna de corte industrial y ferroviario, con valores de orden histórico, arquitectónico, tecnológico y científico, como también simbólico y testimonial, es un reflejo de lo que fue la vocación y desarrollo industrial de la capital de Antioquia durante casi un siglo (figura 6).

Figura 4. Estación El Bosque y Parque Explora

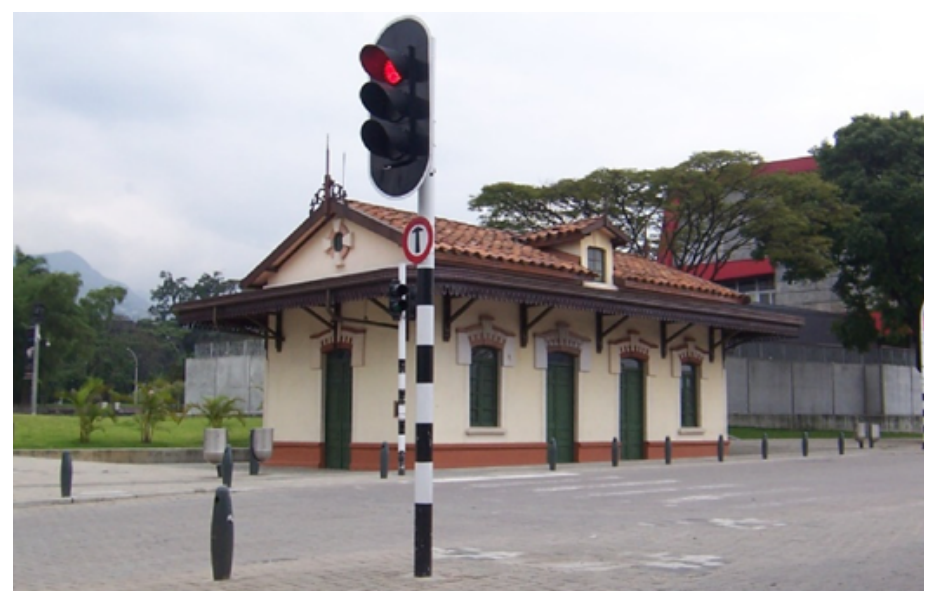

Fuente: elaboración propia (2015).

Figura 5. Estación Santiago y micro central hidroeléctrica

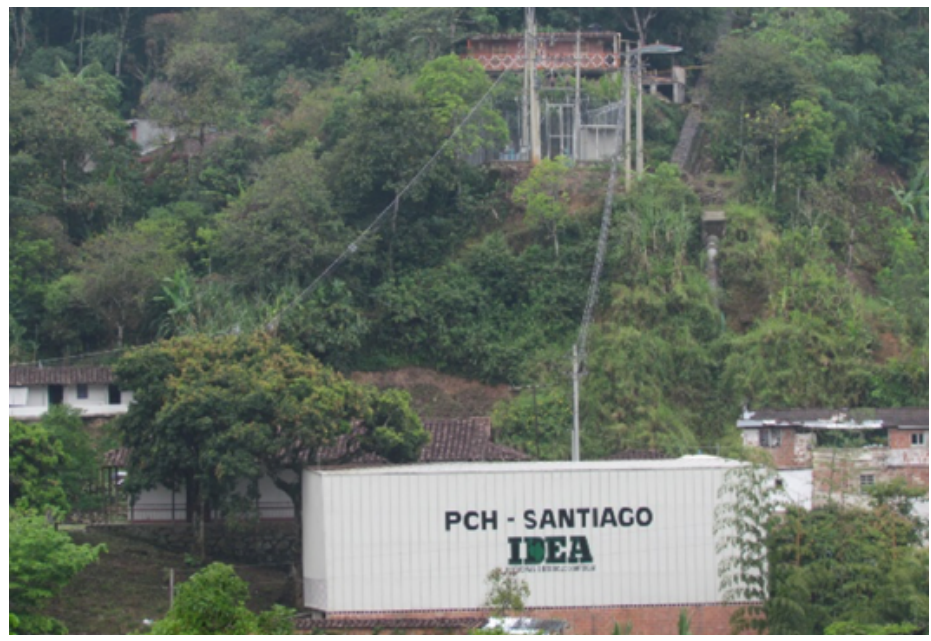


Figura 6. Edificio de Talleres Diesel, centro del conjunto ferroviario

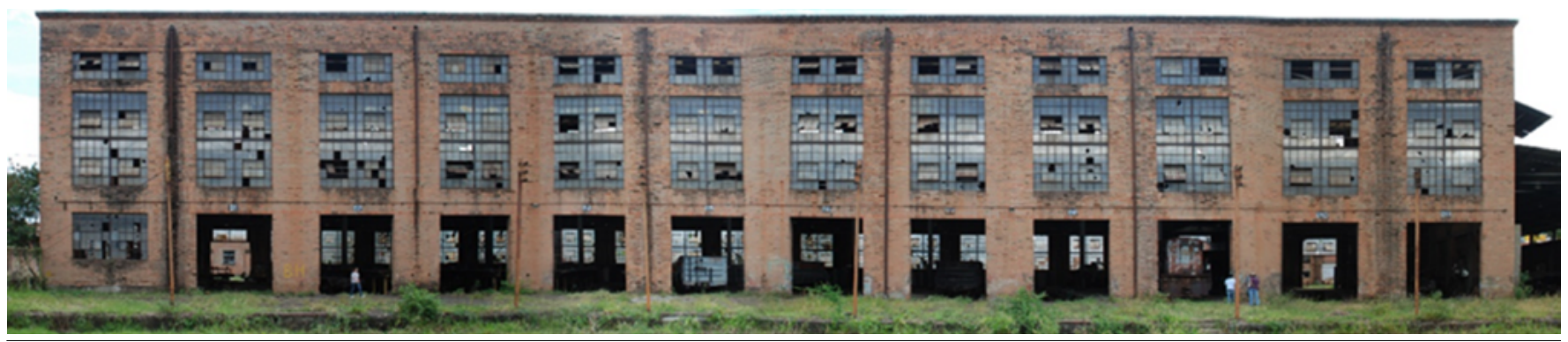

Fuente: elaboración propia (2016).

Gracias a su ubicación geoestratégica y emplazamiento - una extensión de ocho hectáreas-, consecuente potencial de articulación al desarrollo urbanístico y territorial del municipio de Bello y el área metropolitana, los Talleres, han despertado el interés de los diferentes gobernantes, instituciones, actores sociales, planificadores y grupos inmobiliarios, en un escenario complejo de disputas por su titularidad, control y manejo, dejando de lado toda reflexión ampliada de ciudad y territorio, donde prevalezca la mirada integral y holística del patrimonio cultural, en sintonía con sus valores esenciales y el desarrollo urbano del municipio. Para ello, ha sido necesario anteponer a la reflexión, la relación entre patrimonio y desarrollo desde una perspectiva sostenible de la planificación, que permita su aprovechamiento y disfrute ciudadano como un bien redituable social y económico, en el corto, mediano y largo plazo, a fin de establecer, en un escenario ampliado de participación, un equilibrio

\section{territarias 44} armónico entre las demandas y potencial de uso, con sus vocaciones y capacidad de carga (figuras 7, 8, 9, 10, 11 y 12).

Como contextualización del proceso que se ha venido presentando en los Talleres, en el 2009 el Ministerio de Transporte entregó el predio a manera de trasferencia y a título gratuito al municipio de Bello, mediante la Resolución 1463 del 16 abril de 2009, con la condición exclusiva de que fuera destinado como Parque de Artes y Oficios y, delegó a una corporación sin ánimo de lucro - Corporación de Artes y Oficios de Antioquia (Coparte) - su gestión y administración, actualizada en el 2014 con la intención de promover el uso del bien para los efectos de “[...] la creación, el estudio, la práctica, la investigación y la difusión de las diversas manifestaciones artísticas y culturales, en especial para el desarrollo de actividades, instrucción y educación en artes y oficios" (Resolución 2417, 2014). Esta última resolución modifica el artículo $3^{\circ}$, en la posterior resolución 118 de 2016, relacionado con la destinación del bien: 
[...] en el sentido de establecer que la Alcaldía de Bello también podrá destinar el bien inmueble para la gestión de operaciones urbanas dentro del marco de la Ley 1508 de 2012, de Asociaciones Público Privadas y demás normas que lo adicionen, modifiquen o complementen y sus decretos reglamentarios, siempre que se trate, según el objeto de dicha ley (República de Colombia, 2016, p. 3 ).

Para el mismo año, el Concejo $\mathrm{Mu}-$ nicipal de Bello amparado en esta última resolución, mediante el Acuerdo 020 de 2009, ordenó al alcalde transferir al Fondo Nacional del Ahorro (FNA) el inmueble mediante la figura de fideicomiso, con la intención de lograr la utilización efectiva del inmueble. Lo cual se invalidó más adelante en el concepto emitido por el Tribunal Contencioso de Antioquia, mediante la Sentencia SO2-008 de 2018 (Corte Suprema de Justicia, 2018), por considerar que el Concejo extralimitó sus funciones.

Figura 7. Planta de localización del conjunto de Talleres en el contexto municipal de Bello

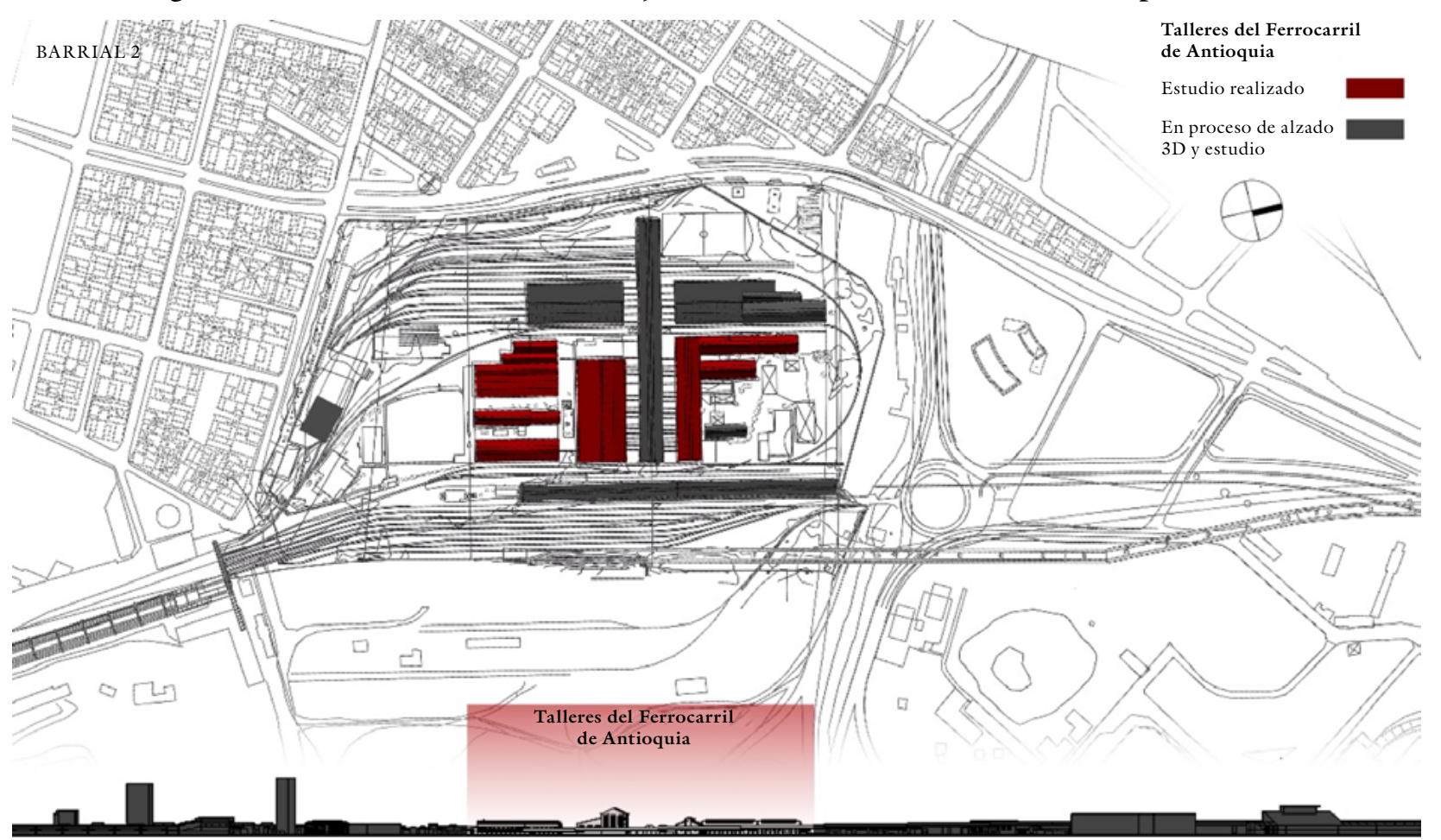

Fuente: semillero de investigación Patrimonio Industrial y Ferroviario (PIF) de la Universidad de San Buenaventura, Medellín (2018). 
Figura 8. Planta general del conjunto de Talleres del ferrocarril en Bello

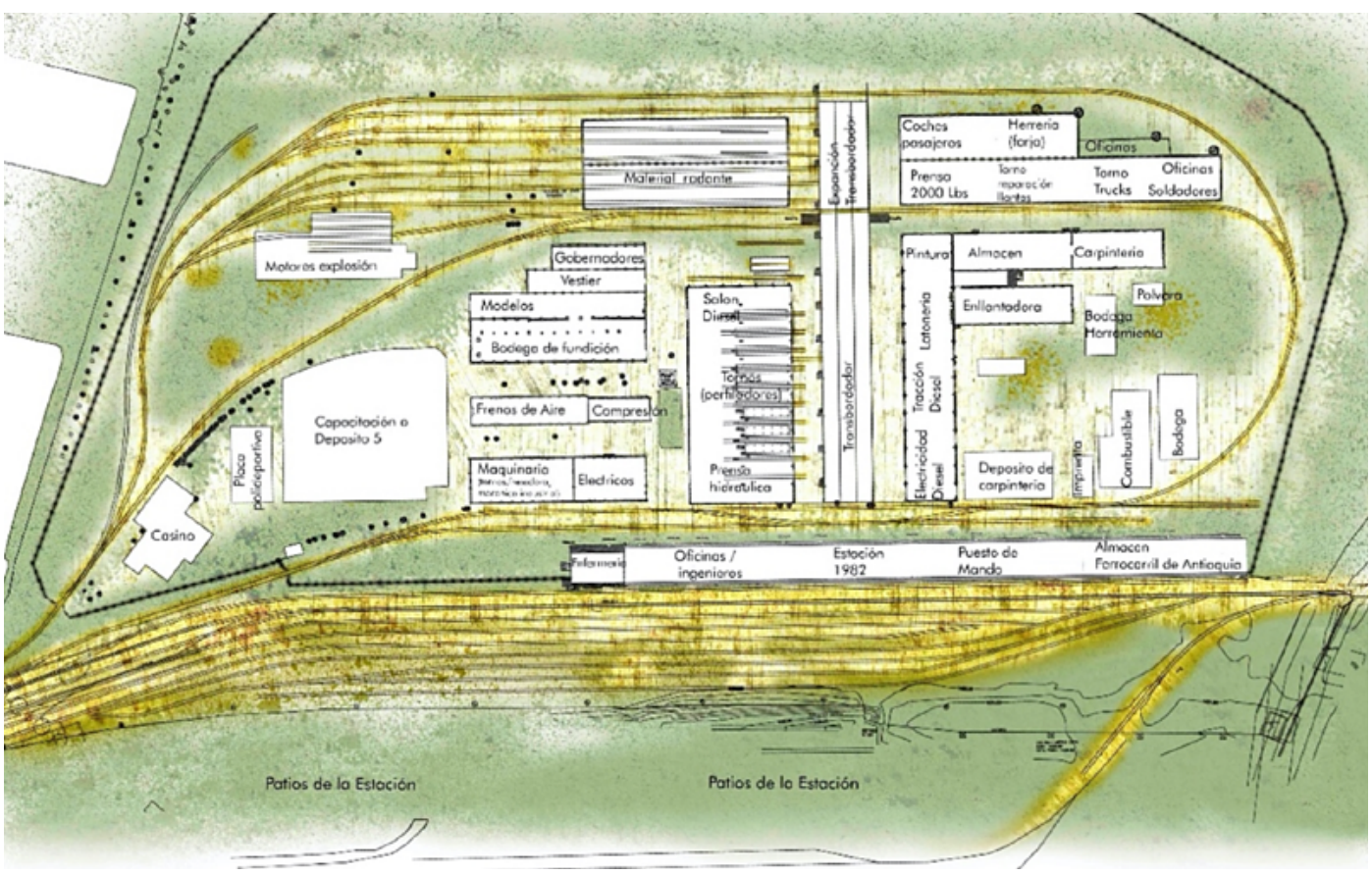

Fuente: semillero de investigación Patrimonio Industrial y Ferroviario (PIF) de la Universidad de San Buenaventura, Medellín (2018).

Figura 9. Vista exterior del edificio de material rodante en los Talleres de Bello

territarias 44

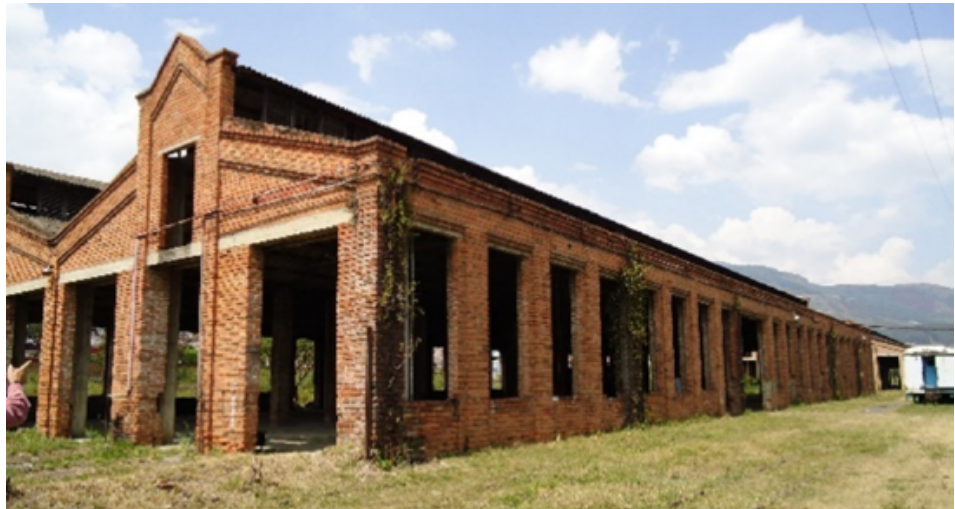


Figura 10. Vista interior del edificio de material rodante en los Talleres de Bello

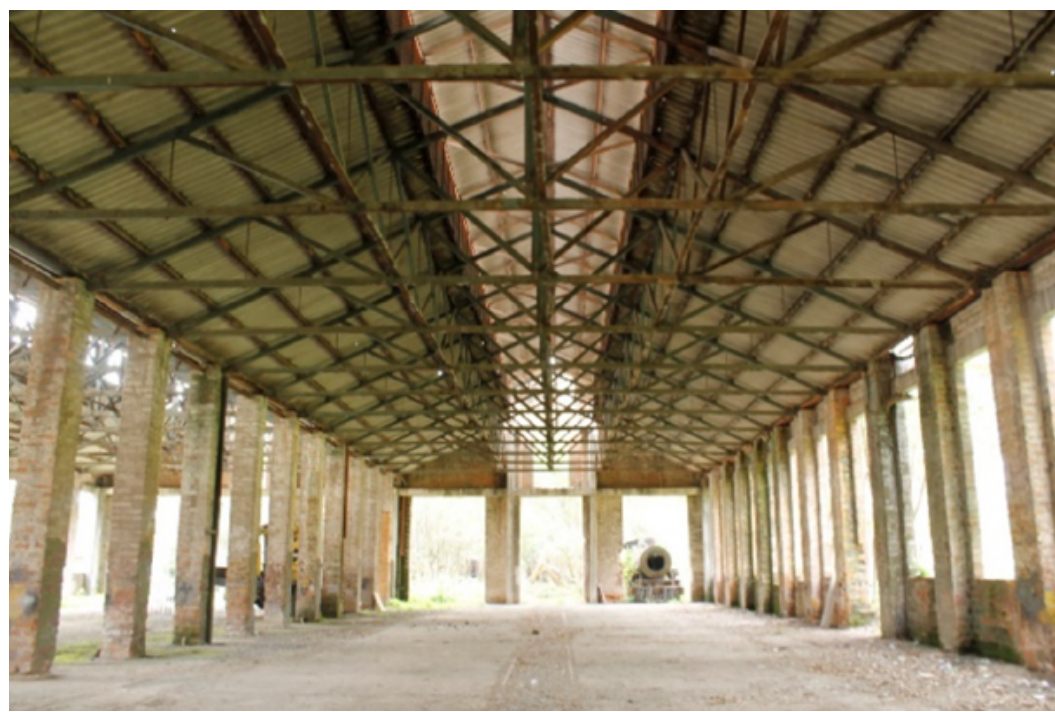

Fuente: elaboración propia (2010).

Figura 11. Vista exterior del edificio de Talleres Diesel en el conjunto de Bello

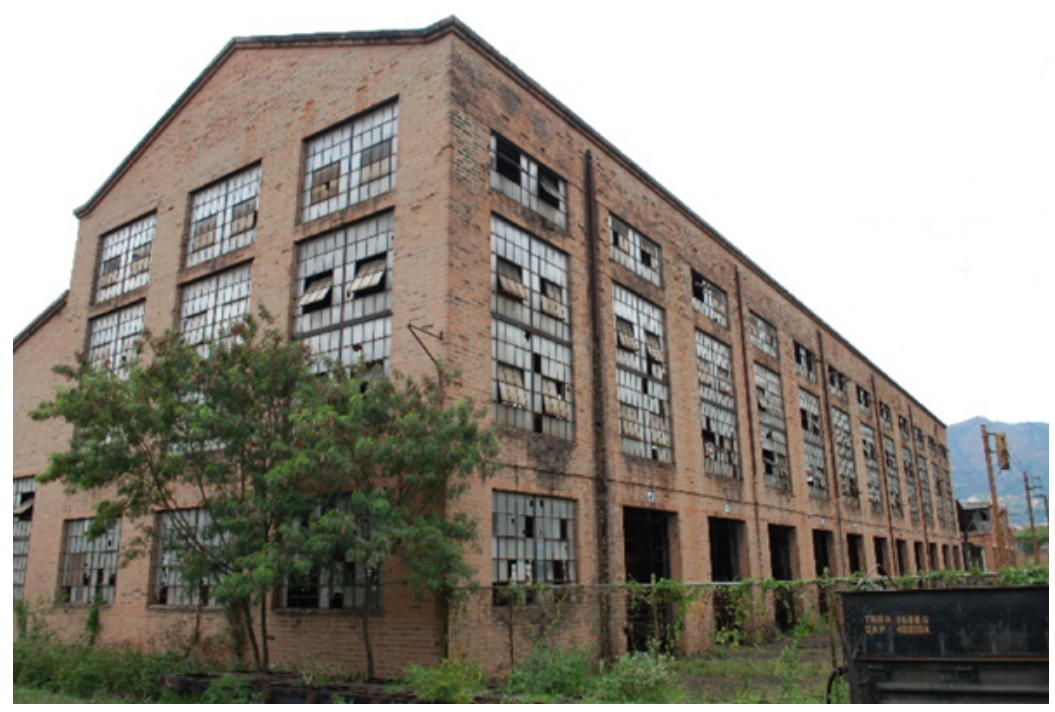

Fuente: elaboración propia (2010).

territarias 44 


\section{Figura 12. Vista interior del edificio de Talleres Diesel en el conjunto de Bello}

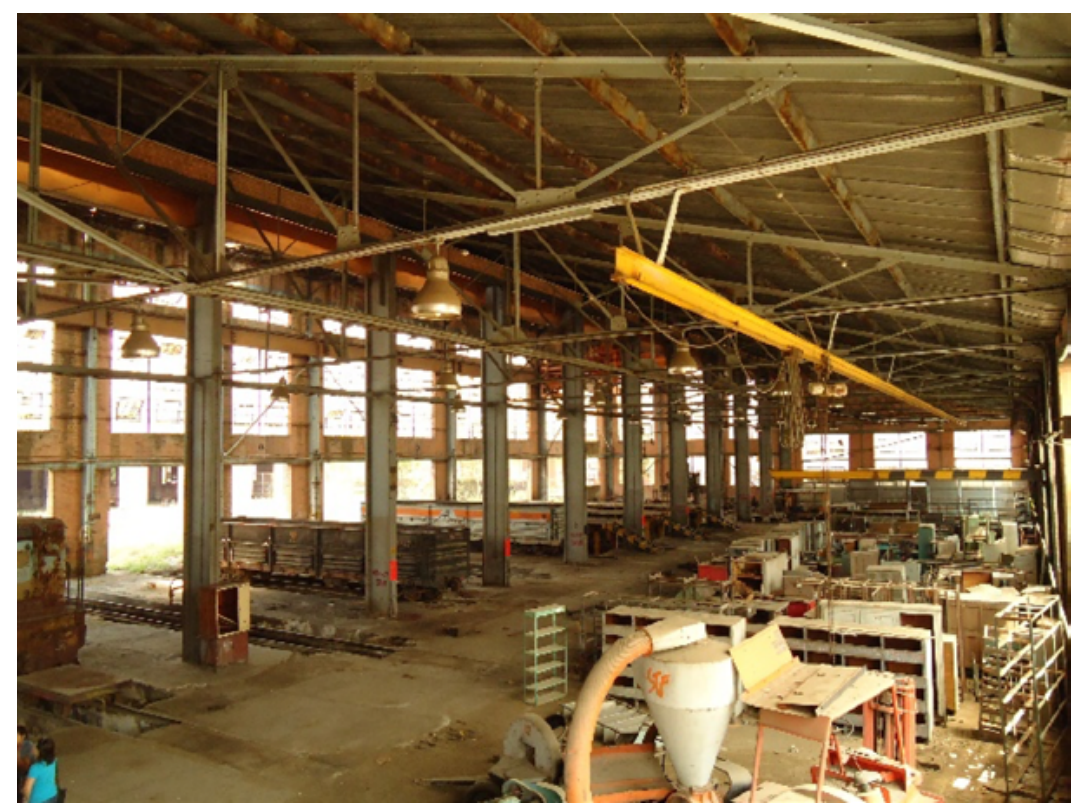

Fuente: elaboración propia (2010).

No obstante, el artículo $3^{\circ}$ de la resolución, deja abierta la posibilidad de la gestión de operaciones urbanas en el inmueble, que si bien plantea la restricción de uso cultural, artístico y educativo antes mencionada, podrá prestarse para muchas interpretaciones, mientras no exista precedente de una declaratoria como Bien de Interés Cultural de la Nación, o incluso, del orden municipal - y de paso, por su escala y valor de conjunto, un plan especial de manejo-, no será posible plantear ningún tipo de operación urbana $\mathrm{y}$, se necesitará de un proceso integral de diagnóstico, valoración y gestión patrimotersitarios 44 286 nial del conjunto, con el debido análisis multidimensional que aplica para cualquier estudio urbano, que se articule con las decisiones que se tomen de restauración, rehabilitación, resignificación y refuncionalización del conjunto.

En este marco es donde surge la necesidad de enriquecer el discurso oficial autorizado con el discurso local y, entrar a considerar los factores humanos y las condiciones del lugar en su escala barrial, municipal y metropolitana, en la medida en que son preexistencias físicas cargadas de memoria y significación, que impactan de forma determinante el paisaje y las estructuras urbanas, y representan los intereses de los ciudadanos. 


\section{A manera de síntesis}

Son varias las interpretaciones y consecuencias del discurso patrimonial autorizado oficial, que terminan por desvirtuar la esencia de la conservación como proceso de activación y puesta en valor. Es hegemónico, centralista y contrariamente segregacionista: excluye otras versiones locales del patrimonio por oponerse o encontrarse fuera de él (Smith, 2011). En la disputa sobre el territorio cultural, se imponen estructuras de poder que plantean imágenes acomodadas al discurso oficial autorizado, dejando de lado el valor de las representaciones o imaginarios sociales locales que emergen naturalmente desde la cotidianidad. Las políticas neoliberales han ido debilitando al Estado cada vez más, para someterlo a las presiones económicas de inversión, explotación y mercantilización del territorio, que están por encima de los intereses de las comunidades y patrimonios locales, a extremos de llegar a su privatización y banalización. Emergen en ellos discursos fragmentados y vacíos de identidad, que solo se concentran en los valores materiales y anecdóticos del patrimonio, ausentes del contexto de territorio y prácticas culturales. En medio de este panorama desigual, se levantan algunas voces de las comunidades que encuentran apoyo, la mayoría de veces, en los colectivos académicos, artísticos y culturales, en general del ámbito local, que pueden llegar a movilizaciones y manifestaciones de disenso necesarias para la construcción de un escenario negociado de acciones sobre el patrimonio. No se trata de lograr consensos en las mayorías, sino de permear los disensos y establecer acuerdos en los desencuentros. Este continente se ha construido históricamente en un ambiente complejo de disputa, pero también, y sincréticamente, de fecundación múltiple de culturas, donde el patrimonio se puede constituir potencialmente en instrumento de paz, convivencia y reconciliación.

Un paralelo entre los discursos oficial y local revela claramente el desequilibrio entre ambos y, plantea una revisión crítica de sus fundamentos y efectos sobre el patrimonio cultural, que impulsa a su revisión (tabla 1$)$.

Tabla 1. Matriz analítica sobre los fundamentos y efectos de los discursos oficial y local del patrimonio

\begin{tabular}{|l|l|}
\hline \multicolumn{2}{|c|}{ Patrimonio cultural } \\
\hline \multicolumn{1}{|c|}{ Discurso oficial } & \multicolumn{1}{c|}{ Discurso local } \\
\hline $\begin{array}{l}\text { Se construye desde la } \\
\text { institucionalidad. }\end{array}$ & $\begin{array}{l}\text { Se construye desde } \\
\text { los sujetos en las } \\
\text { cotidianidades e } \\
\text { imaginarios sociales. }\end{array}$ \\
\hline $\begin{array}{l}\text { Es expresión de } \\
\text { nacionalidad. }\end{array}$ & Es expresión de lo local. \\
\hline $\begin{array}{l}\text { Privilegia las formas de } \\
\text { conocimiento y valores } \\
\text { que le han sido otor- } \\
\text { gados: es excluyente. }\end{array}$ & $\begin{array}{l}\text { Dialógico y } \\
\text { participativo: es } \\
\text { incluyente. }\end{array}$ \\
\hline $\begin{array}{l}\text { Es autoritario, } \\
\text { hegemónico y } \\
\text { nacionalista. }\end{array}$ & $\begin{array}{l}\text { Es democrático y } \\
\text { abierto a la diversidad } \\
\text { y multiculturalidad. }\end{array}$ \\
\hline
\end{tabular}

territarias 44

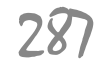




\begin{tabular}{|c|c|}
\hline \multicolumn{2}{|c|}{ Patrimonio cultural } \\
\hline Discurso oficial & Discurso local \\
\hline $\begin{array}{l}\text { Se constituye en un } \\
\text { discurso prestado por } \\
\text { otros y es ajeno a las } \\
\text { prácticas culturales. }\end{array}$ & $\begin{array}{l}\text { Es dialógico y } \\
\text { participativo: promueve } \\
\text { el diálogo de saberes } \\
\text { y se incorpora a las } \\
\text { prácticas culturales. }\end{array}$ \\
\hline $\begin{array}{l}\text { Se corre el riego de } \\
\text { la banalización. }\end{array}$ & $\begin{array}{l}\text { Es auténtica expresión } \\
\text { de apropiaciones y } \\
\text { significaciones locales. }\end{array}$ \\
\hline $\begin{array}{l}\text { Es estático, único, } \\
\text { inmutable e inalterable: } \\
\text { finito, frágil y } \\
\text { no renovable. }\end{array}$ & $\begin{array}{l}\text { Es dinámico, flexible } \\
\text { y puede resignificarse } \\
\text { o renovarse. }\end{array}$ \\
\hline $\begin{array}{l}\text { Se cosifica: privilegia } \\
\text { lo material. }\end{array}$ & $\begin{array}{l}\text { Combina lo material } \\
\text { con lo inmaterial. }\end{array}$ \\
\hline $\begin{array}{l}\text { Niega la diversidad y } \\
\text { privilegia la unicidad. }\end{array}$ & $\begin{array}{l}\text { Establece una relación } \\
\text { dialéctica entre } \\
\text { identidad y alteridad: } \\
\text { lo que nos hace } \\
\text { iguales, y a su vez, } \\
\text { diferentes. Diversidad. }\end{array}$ \\
\hline $\begin{array}{l}\text { Se constituye en } \\
\text { "lastre" para el mal } \\
\text { llamado "desarrollo". }\end{array}$ & $\begin{array}{l}\text { Se constituye en } \\
\text { una oportunidad } \\
\text { para el desarrollo. }\end{array}$ \\
\hline $\begin{array}{l}\text { Reduce la escala e } \\
\text { impacto del patrimonio } \\
\text { y lo restringe a las } \\
\text { unidades seleccionadas. }\end{array}$ & $\begin{array}{l}\text { Amplía el ámbito } \\
\text { de influencia de } \\
\text { los patrimonios } \\
\text { al territorio y } \\
\text { contexto cultural. }\end{array}$ \\
\hline
\end{tabular}

Fuente: elaboración propia.

\section{Nuevos desafíos}

En el marco internacional de la Unesco emerge el protagonismo que comienza a ocupar el patrimonio inmaterial, tradicio- y comunidades rurales alejadas del mundo occidental, y la necesidad de generar un correlato de los patrimonios materiales y centralidades urbanas. Esta discriminación o segregación conlleva a un discurso fragmentario e incompleto que obliga a revisar las categorías de patrimonio, e incorporar en ellas el diálogo en doble vía, intersubjetivo de imaginarios, conocimiento y saberes, que permitan enriquecer los valores patrimoniales e incorporarlos no solo al relato histórico, sino al espacio, como lo expresa Santos (2000) "percibido, sentido y vivido", en su hibridación de objetos y acciones. De allí la generación de nuevas categorías como los paisajes e itinerarios culturales, que plantean un ejercicio de integralidad entre el territorio, la comunidad y la cultura.

Se abre entonces una puerta hacia la construcción social del patrimonio desde lo local, en estrecha relación con el territorio, la comunidad y la cultura, mediado por procesos de participación en la tarea de reconocimiento, valoración y activación de un patrimonio incluyente, que permita un diálogo convivencial y abierto de saberes y negociaciones - entre consensos y disensos-, como estrategia para superar las disputas territoriales entre los diferentes actores; entendido como un acto político de gestión del patrimonio y proceso real de desarrollo y transformación del territorio.

Las ideas de participación que emergen de los procesos de patrimonialización, han demostrado que es posible lograr el equilibrio entre cultura y desarrollo, 
entendiendo el patrimonio como catalizador sobre la base del bienestar humano en comunión con el territorio cultural, y para ello, algunas consideraciones que pueden contribuir a lograrlo son:

- Trascender el paisaje de su condición estática (como herencia), al territorio cultural (como espacio existencial), y por tanto, al patrimonio territorial cuando este adquiere significado para las generaciones pasadas y sentido para las futuras.

- Promover una mirada interdisciplinar, holística y multidimensional de los diferentes componentes, como aporte al relato y discurso patrimonial.

- Reconocer que los procesos de participación se enriquecen de la investigación, en la medida en que los investigadores se constituyen en sujetos activos del proceso.

- Convocar las voces de los actores a partir de los asuntos de la cotidianidad, los diálogos de saberes y los imaginarios locales, como correlato y construcción integral de identidad.

- Encontrar y desarrollar críticamente categorías integradoras de los patrimonios material e inmaterial al discurso de patrimonialización. Por ejemplo, paisajes e itinerarios culturales.

- Promover la educación patrimonial en la cátedra escolar y municipal que incorpore las historias locales y la comprensión del territorio cultural.
- Reconocer que las soluciones a los problemas no son creaciones a priori, sino que pueden tener su respuesta en las mismas comunidades: los patrimonios no se crean, se construyen.

El concepto de gestión, entendido en su acepción participacionista, alude a toda acción(es) y proceso(s) humano(s) encaminado a la obtención de un fin determinado, que, llevado al asunto del patrimonio cultural, se asienta en la idea de la activación o puesta en valor de bienes de interés cultural que incorpore sus valores esenciales, apropiaciones y significaciones, en un diálogo armónico y abierto entre la memoria y los imaginarios de las sociedades que lo han disfrutado y heredado. En términos prácticos, alude a las técnicas e instrumentos que facilitan el desarrollo cultural y, se constituye en el lugar común de redes de trabajo, con capacidad para desarrollar proyectos y acciones de planificación, administración, evaluación y control social del patrimonio.

En esta perspectiva, García Canclini (1989) habla del paradigma participacionista en la gestión del patrimonio como rédito social, que trasciende las versiones tradicionalista, mercantilista y monumentalista, en su relación con las necesidades globales de la sociedad. El capital más preciado del patrimonio cultural está representado en sus comunidades, no solo como sujetos portadores de memoria, sino como agentes de cambio y activación, 
por ello la necesidad de acoger sus voces en los procesos de patrimonialización. En consecuencia, lo mencionado obliga reconocer en el orden local que la capacidad de gestión y de autogobierno, depende en buena medida de la incorporación de la planeación participativa, un espacio ganado por las propias comunidades para la toma de decisiones y la búsqueda de una mejor calidad de vida.

\section{Referencias}

Choay, F., \& Connell, L. M. (2001). The Invention of the Historic Monument. Cambridge University Press.

Comerci, M. E. (2004). Formas, representaciones, actores sociales y procesos en Chos Malal. Huellas, 9(139), 135-162. http://www.biblioteca.unlpam.edu. ar/pubpdf/huellas/n09a07comerci. pdf

Congreso de Colombia. (1997, 7 de agosto). Ley General de Cultura. [Ley 397 de 1997]. D. O: 43.102. http://www. suin-juriscol.gov.co/viewDocument. asp? ruta $=$ Leyes $/ 1659563$

Congreso de la República. (2008, 12 de marzo). Modificación Ley General de Cultura. [Ley 1185 de 2008]. D. O: 46.929. http://www.secretariasenado.gov.co/senado/basedoc/ ley_1185_2008.html

García Canclini, N. (1987). ¿QQuiénes usan el patrimonio? Políticas culturales y participación social. Antropologia, 15,
11-24. https://www.bcin.ca/bcin/ detail.app?id $=413461$

Jaramillo Uribe, G. (2016). Acercamiento a un modelo de gestión patrimonial del Ferrocarril de Antioquia como itinerario cultural: Trayecto Botero-Cisneros. Universidad de Granada.

Ministerio de Transporte. (2009, 16 de abril). Resolución n. 1463.

Ministerio de Transporte. (2014, 15 de agosto). Resolución n. ${ }^{\circ}$ 2417. Por la cual de modifica el articulo 3 de la Resolución 001463 del 16 de abril de 2009 expedida por el Ministerio de Transporte. http:// web.mintransporte.gov.co/jspui/bitstream/001/6553/1/RESOLUCION 2417-2014.pdf

Ministerio de Transporte. (2016, 4 de enero). Resolución n. ${ }^{\circ} 118$.

Prats, L. (2005). Concepto y gestión del patrimonio local. Cuadernos de Antropología Social, (21), 17-35. https:// doi.org/10.34096/cas.i21.4464

Santos, M. (2000). La naturaleza del espacio: técnica y tiempo, razón y emoción. Ariel.

Smith, L. (2011). El “espejo patrimonial”. ¿Ilusión narcisista o reflexiones múltiples?. Antipoda. Revista de Antropología y Arqueologia, (12), 39-63. https://doi.org/10.7440/antipodal2.2011.04

Unesco. (1998). Conferencia intergubernamental sobre politicas culturales para desarrollo. Informe Final. http://www.lacult.unesco. 
org/docc/1998_Conf_Intergub_sobre_pol_cult_para_des.pdf

Universidad de San Buenaventura, Instituto de Cultura y Patrimonio de Antioquia, Alcaldía del municipio de Cisneros, Alcaldía del municipio de Santo Domingo \& Gobernación de Antioquia. (2013). Inventario de patrimonio arqueológico industrial y ferroviario. Ferrocarril de Antioquia: Trayecto Botero-Cisneros. Universidad de San Buenaventura. https://cutt.ly/QgLK81F 